emergency. However, in the past 18 years in medical circles the term accident and emergency has come to designate precisely what previously had been called casualty. This stems directly from the Platt Report's second recommendation. In the ensuing years it has gained such widespread acceptance in the United Kingdom that one searches with difficulty for any trace of the word casualty in an authoritative contemporary document on this subject such as the Lewin Report, ${ }^{4}$ where it appears briefly on page 23 , referring to small peripheral departments, but where in all other paragraphs the term accident and emergency is used.

Maybe the discussion on page 4 of our book ${ }^{5}$ on the use and misuse of accident and emergency departments does lack the clarity and forcefulness which $\mathrm{Mr}$ Abson desires. However, I cannot believe that clarity and forcefulness would have been well served by substituting the word casualty for either "emergency" or "accident and emergency," or by defining casualty in terms of "community dependence" described as "the need of immediate assistance from the independent citizen."

WILLIAM RUTHERFORD Accident and Emergency Department, Royal Victoria Hospital,
Belfast BT12 6BA

Subcommittee of the Standing Medical Advisory Committee of the Central Health Services Counci. Accident and emergency services. London: HMSO 1962:23-4, 39. (Platt Report.)

Anonymous. Lancet $1869 ; \mathrm{ii}: 577$.

Anonymous. Lancet 1869 ;ii:613. services. Medical staffing of accident and emergency services.

sutherford WH, Nelson PG, Weston PAM, Wilson DH. Accident and emergency medicine. Tunbridge Wells: Pitman Medical, 1980:4

\section{Open-access endoscopy}

SIR,-Mr M W L Gear and others (3 May, p 1135) justify their open-access endoscopy service by their success in finding organic lesions. A cynic has defined a healthy person as "someone who has not been fully investigated." Their article does not show the effect of the investigation on the patient or how relevant they considered, for example, the mucosal lesions.

Gastroenterologists find that many dyspeptics have no relevant organic lesion and are cured by instant reassurance supported, when necessary, by barium meal or endoscopy. These have suffered in the past from being wrongly labelled as victims of visceroptosis, chronic appendicitis, chronic cholecystitis, or hiatus hernia (without objective evidence of reflux). Obviously, the endoscopist will find more satisfaction in "finding something"; but much mucosal disease like gastritis is irrelevant and found in normal people, or a reddened mucosa may be a reaction of the psyche to endoscopy. If an unnecessary organic label is given, neurosis may be perpetuated and patients may be condemned to dieting or cimetidine instead of being cured by reassurance.

So open-access endoscopy can do harm. The ill effect of new technology has been shown in other specialties; for example, the electrocardiogram produced many invalids in the early days before the normal variations were known.

Clifford Hawkins

Queen Elizabeth Hospital

Birmingham B15 2TH
Low-tar smoking versus middle-tar smoking

SIR,-Dr M A H Russell and others (5 April, p 972) report an important study which, albeit in a highly selected population, indicates that smokers of ventilated (low-tar) cigarettes smoke their products more intensively than smokers of unventilated (middle-tar) cigarettes when the products have been both self-selected and smoked over a relatively long period of time.

The results presented, however, based primarily on the measurement of blood nicotine, do not wholly support the authors' conclusion that tar intake is not appreciably lower in the low-tar smokers than in middletar smokers. Despite a high (statistical) correlation between the tar and nicotine yields of manufactured cigarettes the tar:nicotine ratio can by no means be considered a constant. On the basis of table IV of the paper the middle-tar and low-tar products have, on average, tar:nicotine ratios of 13.77 and 11.63 respectively. Thus even if smokers achieved the same levels of nicotine from the low-tar cigarettes as from the middle-tar cigarettes, their tar intake would remain on average lower by $16 \%$. In fact, the levels of blood nicotine measured in the low-tar cigarette smokers are for men $87.5 \%$ and for women $95 \%$ of the values found in the middle-tar cigarette smokers; on the basis of these levels the corresponding relative tar intakes would be $73 \%$ for men and $80 \%$ for women (one would expect a relative nicotine intake of $62 \%$ and a relative tar intake of $52 \%$ if the cigarettes were smoked under comparable standard conditions). Therefore although the nicotine intake by lowtar cigarette smokers may not be appreciably lower than that of middle-tar cigarette smokers it does not follow that the same is true for tar intake.

It might be argued that this could support the hypothesis that has been advanced that maintenance of nicotine intake determines the intensity of smoking but whether this is true or not, the smoker-if he cannot stop smoking - should be encouraged to smoke not only a lower-tar product but also one with a lower tar: nicotine ratio.

ROGER G RAWBONE

Physiology Department, Queen's University of Belfast,

\section{Carbon monoxide yield of cigarettes}

SIR-Dr N J Wald and Sir Richard Doll disagreed with Mr P N Lee's statement that there seems to be no strong case for the publication of carbon monoxide (CO) yields on the grounds that the values would be useful to physicians who wish to advise smokers to reduce their exposure (1 March, p 646). We question the general assumption that numbers for quantities such as cigarette tar, nicotine, and $\mathrm{CO}$ are a good indication of potential brand toxicity.

Estimations for cigarette yields are provided by smoking machines, which take a $35 \mathrm{ml}$ puff of two-second duration once every 60 seconds until a fixed butt length is reached. These conditions are probably a poor reflection of current human behaviour, particularly for those smokers who "compensate" when they switch brands" ; as Drs $M$ J Jarvis and $M A H$ Russell point out in their comment on the Hunter Committee's second report (5 April, p 994), there is much evidence that people do not smoke cigarettes in the same way that smoking machines do.

The utility of these standard numbers may be questioned on other grounds as well. The Canadian Government has recently released the $\mathrm{CO}$ yields of cigarettes and, on the basis of these results, we have defined a group of lowhazard cigarettes, average CO yield $10.9 \mathrm{mg}$ (range 1.7 to $14.8 \mathrm{mg}$ ), and high-hazard cigarettes, average CO yield $23.0 \mathrm{mg}$ (range 20.7 to $24.4 \mathrm{mg})^{2}$ We have also determined levels of carboxyhaemoglobin for two groups smoking similar numbers of both types of cigarettes ("low" $19 \pm 2$ and "high" $19 \pm 3$ cigarettes per day) and found no difference. The average for smokers of the "low" CO yield brands was $4.7 \pm 0.8 \%$ and $5.0 \pm 0.8 \%$ for those smoking the brands defined as "high" yield. If this result is substantiated by further studies, then it would be difficult to escape the conclusion that behavioural factors are far more important than cigarette yields in determining exposure and the risk of smoking-related diseases. Obviously in order to answer this question $\mathrm{CO}$ yields must be made public.

\section{WILIIAM RICKERT} JACK ROBINSON

Smoking and Health Program,

Labstat Incorporated, Canada

1 Schulz W, Seehofer F. In: Thornton RE, ed. Smoking behaviour, physiological and psychological influences. Edinburgh: Churchill Livingstone, 1978:259-76. 2 Rickert WS, Robinson JC, Young JC. F Toxicol
Environ Health 1980;6:353-67.

\section{A computer in every surgery?}

SIR,-The leading article "A computer in every surgery ?" (28 June, p 1556) is in our opinion a retrogressive contribution to the debate on the role of computers in general practice. It fails to recognise the very real changes in record keeping which have occurred over the last few decades in a large number of practices. It fails to recognise the importance of information systems to assist practice management, the process of care, surveillance of chronic conditions, and clinical audit. It fails to recognise the rapidly changing world in which we live and, finally, it fails to recognise the far-reaching changes in general practice which will have to materialise if the GP is to retain his position as the main provider of primary care.

It is just not possible for the general practitioner's surgery to remain a haven from modern society. Our role in society is largely determined by our patients and we ignore their needs and wishes at our peril. A recent example of our failure to meet this need is over the matter of blood pressure measurement. We inform the public that untreated high blood pressure leads to an increased chance of a stroke, yet we deny them the opportunity to receive regular blood pressure checks because we are too busy for routine screening procedures. Our patients, therefore, turn to the supermarkets and chemists where a machine takes their blood pressure. If we do have to resort to such a machine to take blood pressures, then surely it should be situated in the doctor's surgery. With an increasing awareness of risk factors, and the need for informed advice for all patients, including the obese, smokers, and women over 35 years taking the contraceptive pill, the GP who does not record these facts and advise his 